it is this variety that will be dwelt upon. By no means seldom, patients having an excess of mucus in the conjunctival sac, due to an inflammation of the conjunctiva, and very likely of the tear passage, complain at times of diplopia on looking at oljects near to, as in reading. The same annoyance is sometimes produced by pterygium, irregularity in the curvature of the cornea after a wound, coloboma of the iris (a congenital slit, due to arrest of development), luxation of the lens, and congenital irregular astigmatism. It has been frequently observed by oculists in incipient senile cataract.

In my notes, taken in the last three or four years, of the examinations of ninety-two patients having ordinary incipient cataract, the following abnormalities are recorded : diplopia, nineteen ; myopia, four ; polyopia, two ; irregular astigmatism, five. Males, ten; females, twenty. Of the thirty persons who noticed refractive defects, twenty-five were private patients, while but five of the thirty cataract patients seen at the Salem Hospital had remarked anything abnormal. This was possibly due to a want of observation on their part, and the same reason may have accounted for the small number of males who reported visual troubles. The writer is aware that these few examples are insufficient for any statistical value, but their publication may tend somewhat to allay alarm at the presence of diplopia (as in seeing " two moons") in a person who has previously enjoyed both health and sight.

A word as to the cause of this form of double sight. It is well known, at least among specialists, that in the beginning of senile cataract the affected eye may become myopic by the alteration in the curvature of the lens, brought about, perhaps, by a swelling of its substance, owing to some defect in exosmosis through the capsule. (This state of refraction is sometimes so marked that - as has occurred in two of my patients - a very considerable degree of help to vision is found by wearing concave glasses.)

So, too, diplopia, polyopia, irregular astigmatism, etc., are doubtless occasioned by an irregular swelling or imbibition of certain sectors of the lens. That it is monocular, and is not dependent on any central trouble, is found by alternately closing first one eye and then the other. In binocular diplopia vision becomes single on closing either eye, while in monocular diplopia the vision is single only when the affected eye is covered.

SALEM, MAss.

David Coggin, M. D.

\title{
PSEUDO-HYPERTROPHIC PARALYSIS.
}

Mr. Editor, - In Bath, Grafton County, is"a case of pseudo-hypertrophic paralysis in a male aged fourteen years. The muscles of the thighs are affected. The disease has been in progress three years, and there is now complete paralysis of all the muscles of the legs. No similar affection in the family, near or remote. The boy often "went swimming," and had a severe contusion upon the lower spine some time before the symptoms of paralysis appeared. Treatment by massage and electricity has been without good result. These cases are so rare that $I$ have thought it worth reporting. The case has been seen and diagnosticated by Dr. Tuttle, of Littleton, N. H.

William Child, M. D.

\section{YELLOW FEVER.}

Mr. Editor, - I was mistaken about the date of the attack of Lonisa Creel by yellow fever at Mississippi City. It should be July 6th instead of July 13th.

No case has sickened here since July 29 th. Our dread is rather of inland quarantines than an epidemic.

S. S. HerRick.

New Orleans, August 8, 1879.

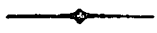

\section{AMNIOTIC FLUID.}

Mr. Editor, - I notice in this week's number of your Jodrnal the report of a case by Dr. Wakefield where there was entire absence of amniotic fluid. The case $I$ think well worthy of note, and I would like to see more of such letters from the profession when finding such abnormalities. In a practice of twelve years $I$ have never met with anything of this kind till the present summer, the principal points of which I will give. The first case occurred July 3, 1879. Mrs. B., a primipara, aged thirty-nine and a half years, after a labor 